\section{Моделирование логистических операций снабжения деревообрабатывающего комбината сырьем на основе сетевого графика}

\author{
В. М. Костюкевич ${ }^{1}$ \\ Петрозаводский государственный университет
}

\begin{abstract}
АННОТАЦИЯ
В статье приводится пример моделирования операций при снабжении деревообрабатывающего комбината на основе сетевого графика. Расчеты на основе сетевого графика позволяют определить ранние моменты наступления событий, установить наиболее ответственные операции, задержка которых может привести к срыву общего графика, распределить ресурсы для эффективного выполнения работ по снабжению древесиной деревообрабатывающего комбината
\end{abstract}

Ключевые слова: сетевой график, операции логистики, критический путь.

\section{SUMMARY}

The article is devoted to modeling of logistics operations on supply of woodworking enterprise with raw materials. It is made on the basis of net graphic. Net graphic allows to define the plan of operations.

Keywords: net graphic, logistics operations, critical way.

\section{ПОСТАНОВКА ПРОБЛЕМЫ}

Основной объект в планировании логистических операций по снабжению сырьем это проект работ с указанием очередности и наименьшего возможного времени их выполнения. Математическая модель сетевого графика основана на построении сети, дуги которой соответствуют работам, а вершины событиям. Событие наступает по завершению некоторой логистической операции. Расчеты на основе сетевого графика позволяют определить ранние моменты наступления событий, установить наиболее ответственные операции, задержка которых может привести к срыву общего графика, распределить ресурсы для эффективного выполнения работ по снабжению древесиной деревообрабатывающего комбината. Моделирование операций на основе сетевого графика позволяет осуществлять контроль выполняемых работ и полезно при составлении расписания работы производств.

Примем следующие допущения: событие не имеет продолжительности; оно может быть простым (одна операция) или сложным (более одного события). Среди событий всего сетевого графика выделим исходное и завершающее события. Исходное событие

\footnotetext{
${ }^{1}$ Автор - доцент кафедры технологии металлов и ремонта

(C) В. М. Костюкевич, 2003
}

не имеет предшествующих операций и событий, а завершающее - последующих.

Последовательность работ, начинающихся исходным событием и заканчивающихся завершающим, обозначим через «путь». Длина любого пути равна сумме продолжительностей составляющих его операций. От начального события к конечному можно построить несколько путей различной протяженности. Путь, имеющий наибольшую временную протяженность, называется критическим. Критическими называются также события и операции, расположенные на критическом пути. Пути, имеющие продолжительность, близкую к продолжительности критического пути, называются подкритическими, а остальные - ненапряженными.

Для каждого события определяются:

- $\quad$ ранний срок наступления $T_{p}$ - возможно ранний момент наступления данного события при заданных продолжительностях операций и начальном моменте;

- $\quad$ поздний срок наступления $T_{n}-$ максимальный из допустимых моментов наступления данного события, при котором еще возможно выполнение всех последующих работ с соблюдением планового срока наступления завершающего события. Определяется разностью между длительностью критического пути и продолжительностью максимального пути, следующего за этим событием до завершающего события сети;

- $\quad$ резерв времени $R$ - допустимый срок, на который можно задержать наступление этого события, не вызывая при этом увеличения срока выполнения всего комплекса операций; определяется как разность между поздним и ранним сроками его наступления.

Для каждой операции определяются:

- ранний срок начала $t_{p w}$ он совпадает с ранним сроком наступления начального события;

- $\quad$ ранний срок окончания $t_{p o}$ - превышает ранний срок ее начала на величину продолжительности этой работы;

- $\quad$ поздний срок начала $t_{n н}-$ меньше позднего срока ее окончания на величину продолжительности этой работы;

- $\quad$ поздний срок окончания $t_{n o}-$ совпадает с поздним сроком наступления ее конечного события;

- общий резерв времени $R_{\mathrm{o}}$ - максимальное время, на которое можно отсрочить начало или увеличить продолжительность операции, не изменяя заданный срок наступления завершавшего события. Он равен резерву максимального из путей, проходящего через эту операцию;

- частный резерв времени $R_{u}$ - максимальное время, на которое можно отсрочить начало или увеличить продолжительность работы при условии, что все события сети наступают в свои ранние сроки. 


\section{РЕАЛИЗАЦИЯ МОДЕЛИ}

Рассмотрим пример применения сетевой модели и графика в логистической системе деревообрабатывающего комбината при планировании обеспечения сырьем. В таблице 1 приведены индекс, содержание и продолжительность операций по обеспечению комбината древесиной для дальнейшей переработки. В соответствии с указанными последовательностью и взаимообусловленностью операций сетевой график совокупности операций логистики примет вид, изображенный на рис. 1.

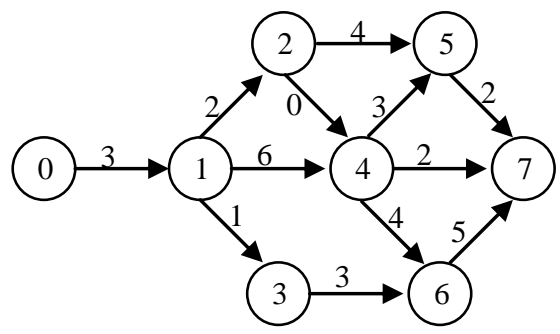

Рис. 1. Сетевой график совокупности операций логистики

Таблица 1

Индекс и содержание операций логистики

\begin{tabular}{|l|l|l|}
\hline $\begin{array}{l}\text { Индекс } \\
\text { опера- } \\
\text { ции }\end{array}$ & \multicolumn{1}{|c|}{ Содержание операции } & $\begin{array}{l}\text { Срок, } \\
\text { дни }\end{array}$ \\
\hline $0-1$ & $\begin{array}{l}\text { Изучение конъюнктуры рынка } \\
\text { древесины }\end{array}$ & 3 \\
\hline $1-2$ & $\begin{array}{l}\text { Выбор лесозаготовителей-постав- } \\
\text { щиков и заключение контракта на } \\
\text { поставку древесины }\end{array}$ & 2 \\
\hline $1-3$ & $\begin{array}{l}\text { Согласование порядка расчетов по } \\
\text { поставкам }\end{array}$ & 1 \\
\hline $1-4$ & $\begin{array}{l}\text { Разработка плана производства } \\
\text { пиломатериалов }\end{array}$ & 6 \\
\hline $2-4$ & $\begin{array}{l}\text { Документальное подтверждение } \\
\text { готовности осуществить поставку }\end{array}$ & 0 \\
\hline $2-5$ & Страхование надежности поставок & 4 \\
\hline $3-6$ & $\begin{array}{l}\text { Контроль качества поставляемой } \\
\text { древесины }\end{array}$ & 3 \\
\hline $4-5$ & $\begin{array}{l}\text { Подготовка складских помещений и } \\
\text { оборудования для приема древесины }\end{array}$ & 3 \\
\hline $4-7$ & $\begin{array}{l}\text { Диспетчеризация материальных } \\
\text { потоков и транспортировки }\end{array}$ & 2 \\
\hline $4-6$ & $\begin{array}{l}\text { Отгрузка материальных ресурсов и } \\
\text { доставка их на комбинат }\end{array}$ & 4 \\
\hline $5-7$ & $\begin{array}{l}\text { Подготовка перегрузочного } \\
\text { оборудования для выгрузки } \\
\text { прибывающей древесины }\end{array}$ & 2 \\
\hline $6-7$ & $\begin{array}{l}\text { Формирование производственного } \\
\text { запаса и запуск древесины в } \\
\text { производство }\end{array}$ & 5 \\
\hline
\end{tabular}

В сетевом графике возможны следующие пути:

$\begin{array}{lll}\text { критический путь } & 0-1-4-6-7 & -18 \text { дней } \\ \text { подкритический путь } & 0-1-4-5-7 & -14 \text { дней } \\ \text { подкритический путь } & 0-1-2-4-6-7 & -14 \text { дней } \\ \text { некритический путь } & 0-1-3-6-7 & -12 \text { дней } \\ \text { некритический путь } & 0-1-2-5-7 & -11 \text { дней } \\ \text { некритический путь } & 0-1-4-7 & -11 \text { дней } \\ \text { некритический путь } & 0-1-2-4-5-7 & -10 \text { дней } \\ \text { некритический путь } & 0-1-2-4-7 & -7 \text { дней }\end{array}$

Временные параметры сетевого графика, выполненные по вышеупомянутой методике, представлены в таблице 2 .

Таблица 2

Временные параметры сетевого графика совокупности операций логистики (в днях)

\begin{tabular}{|c|c|c|c|c|c|c|c|}
\hline 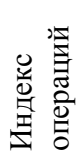 & 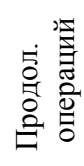 & 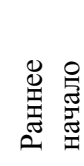 & 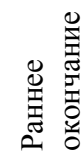 & 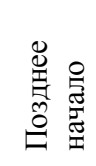 & 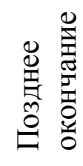 & 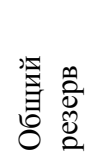 & 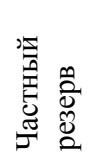 \\
\hline $0-1$ & 3 & 0 & 3 & 0 & 3 & 0 & 0 \\
\hline $1-2$ & 2 & 3 & 5 & 7 & 9 & 4 & 0 \\
\hline $1-3$ & 1 & 3 & 4 & 9 & 10 & 6 & 0 \\
\hline $1-4$ & 6 & 3 & 9 & 3 & 9 & 0 & 0 \\
\hline $2-4$ & 0 & 5 & 5 & 9 & 9 & 4 & 4 \\
\hline $2-5$ & 4 & 5 & 9 & 12 & 16 & 7 & 3 \\
\hline $3-6$ & 3 & 4 & 7 & 10 & 13 & 6 & 6 \\
\hline $4-5$ & 3 & 9 & 12 & 13 & 16 & 4 & 0 \\
\hline 4-7 & 2 & 9 & 11 & 16 & 18 & 7 & 7 \\
\hline $4-6$ & 4 & 9 & 13 & 9 & 13 & 0 & 0 \\
\hline $5-7$ & 2 & 12 & 14 & 16 & 18 & 4 & 4 \\
\hline $6-7$ & 5 & 13 & 18 & 13 & 18 & 0 & 0 \\
\hline
\end{tabular}

После расчета всех параметров и показателей графика определяют дату начала работ и все сроки исполнения привязывают к календарным датам. Если плановый срок совпадает с полученной продолжительностью критического пути, то работу по составлению сетевого графика и расчету его параметров можно считать законченной. Если же полученный срок превышает плановый, следует провести оптимизацию сетевого графика.

\section{СПИСОК ЛИТЕРАТУРЫ}

1. Оптимизация в планировании и управлении предприятиями регионального лесопромышленного комплекса / А. Ф. Булатов, А. В. Воронин, В. А. Кузнецов и др.; ПетрГУ. Петрозаводск, 2001. $227 \mathrm{c}$.

2. Гаджинский А. М. Основы логистики. М., 1997. $124 \mathrm{c}$. 